\title{
Professional Discourses in Information-Communicative Space of Russia: Publicistic Discourse - PR Discourse - Business Discourse
}

Elena Skorohodova

Natalia Shutaya

Larisa Selezneva

Irina Tortunova

Anastasia Rudnitskaya

Russian State Social University, Russia,129226, Moscow, St. Wilhelm Pieck, 4

Doi:10.5901/mjss.2015.v6n5s2p73

\begin{abstract}
Social services are essential for the generation of professional discourse conditions. In the official sphere we identify structural parameters of two levels: the first level, we include a social institution - professional culture; to the parameters of the second level and subject - specific attachment - themed repertoire - genre diversity. In accordance with these arguments, the article discusses the structural parameters of journalistic discourse, PR-discourse and business discourse.
\end{abstract}

Keywords: information and communication space, journalistic discourse, PR discourse, business discourse, the subject system of discourse

\section{Introduction}

Communication presents a complex process, organizing sociocultural space; the communication processes contribute to the creation of the environment by the society - the information-communicative space (Kazaryan, 2011). The information space, being accepted as an important element of this stage of social development, has different definitions. In narrow meaning, the single information space is understood as the space, limited territorially, where the information activity is subject to legal norms. However, the other definitions are widely spread; they consider the information space as a sphere without boundaries and territory. Thus, the Federal Law of RF "About the Participation in International Data Exchange", dated 04.07.1996 \# 85, provides defines the "information sphere (environment)" as the scope of activity of parts, connected with creation, transformation and consumption of information". Information-communicative space is directly connected with the social sphere, which we consider as a combination of institutional or professional discourses. The content of this typology is historically variable: the appearance of new social institute or the new sphere of activity promotes the formation of new discourse.

\section{Procedure}

Under the communicative linguistics, we study the discourse in terms of communicative activity, providing the addressee with an opportunity to interpret the message, and the addresser - to communicate information and to express the thought: "The fact that discourse has this role takes us outside of linguistics per se simply because we have to address how the language of discourse is related to aspects of the communication process that bear an indirect and complicated (as well as controversial) relationship to language per se" (Schiffrin 1990, p. 99). In this case, the study is aimed at the determination and analysis of extralinguistic factors, one of which is the social context.

Social context in the official sphere has a clear professional orientation, i.e. it is determinated by the social institute and presents a type of human communication of definite social, professional group. Such discourse is called professional, and its formation is usually connected with institutionalization of one or another professional sphere, however, the social sphere is an important, but not the single structure-forming parameter.

The scientists distinguish different structure-forming parameters of discourse. Thus, V. Bhatia, apart from the social 
environment, which he names the professional practice, also distinguishes the text, the genre, the professional culture (Bhatia, 2010). Our procedure is based on "the principle of outside", suggested by M. Fuko, according to which, it is necessary to take "the discourse itself as an initial point, its appearance and regularity, and go to outside conditions of its possibility, to the one, that provides place for occasional series of these events and what fixes their boundaries" (Fuko, 1996, p. 80). That is why, analyzing the conditions, required to produce the professional discourse, in the official sphere, we distinguish structure-forming parameters of two levels. The parameters of the first level involve the spheres of social life - social institute - professional culture; we refer the objective belonging - thematic repertoire - genre diversity to the parameters of the second level. Consequently, each type of discourse forms different thematic repertoire, which is understood as the range constraint of possible topics (Deik, 1989, p. 52). In its turn, it influences on the genre system of discourse, thus, the scientific discourse lacks such genres, as financial report, preach, congratulation; articles, dissertations, monographs etc. are typical of it.

Thus, we can present the structure-forming parameters of discourse in the form of net of discursive constraints, which, by means of selection of reality phenomena, form the discourse.

The scheme. Structure-forming parameters of discourse

\begin{tabular}{|l|l|l|l|}
\hline Level 1 & The sphere of social life & Social institute & Professional culture \\
\hline Level2 & Objective belonging & Thematic repertoires & Genre diversity \\
\hline
\end{tabular}

In compliance with the following parameters, let us consider the structure-forming parameters of publicistic discourse, PR-discourse and business discourse.

\subsection{Linguistic peculiarities of publicist discourse}

Culture is frequently interpreted as a system of collective knowledge, by means of which people model the surrounding world. Such viewpoint underlines close interrelation of perception, cognition, language and culture. In line with this concept, the individual actions of people, closely connected by communicative processes, are referred to the complex system of collective knowledge, communicated by means of language (Dmitriev and Makarova, 2003). At present, the mass media is the mediator in distribution of the collective knowledge. Noting the global changes in modern information society, connected with constantly developing possibilities of mass communication, it is necessary to bear in mind, that these changes influence not only on living conditions, but, first of all, on the way of thinking, system of perception of the modern person and his speech (Dmitriev and Latynov, 1999).

The degree of text influence is closely connected with the category of language norm, as the most dominant texts determine the degree of normativityl non-normativity of one or another linguistic phenomenon (Morozova, 2004). As a rule, the main criterion is the presence/ absence of one or another word or grammatical structure in texts, which, at present, are considered to be exemplary, correct. Previously, the pieces of fiction served as such examples, because it was assumed, that the writers treat the language of their pieces consciously and do not make mistakes. However, at present, the authority of literary works, as normative standards, decreased significantly. On the one hand, it is explained by the fact, that due to general decrease of cultural level in the society, going through different social disruptions, the interest to classics decreased significantly. Not all school graduates know the literary pieces, even included to the basis of school curricula. On the other hand, modern fiction creates such texts, which cannot serve as the exemplary yet, cannot form the idea of the norm of literary language, and not everyone has a demand for reading: modern mass culture is oriented at visual perception of brightly moving picture with audio, where the text plays the subordinate role. Even traditional printed media have increased their "visualization", frequently using huge, half-page size photos on each page. Thus, the mass media and those verbal devices, used there, have become the example to follow.

A number of investigators mentioned that fact that, at present, the language of mass media fulfils the function of normalizer. The language of press has great possibilities and has a great impact on the other types of literary language and on the society in whole. For the last fifteen years, the typology, stylistics and language of Russian press has undergone great changes. By the beginning of the XXI century, the language of the mass media becomes the standard norm-creating factor, influencing not only on the formation of norms of modern Russian literary language, but also on ethnic language culture in whole, as the doubtless averaging and massification of speech standard take place.

Thus, at present, the language of modern mass media has a significant impact on the literary language in whole and on speech practice of both society and separate individuum. We have a right to assume that this specificity will be reflected in the peculiarities of mentality, which is being formed at present, i.e in the specificity of worldview orientations of the younger generation, which, at present, uses the mass media as the main source of concepts about the surrounding 
reality. Taking into consideration that fact, the mass media texts are, by nature, the ones, that are oriented at formation of stable concepts; we are to acknowledge, that their influence is very strong. With all teenagers' desire for independence, in this context, for a modern teenager, the communication media has become an important source of information about social world, where he lives. The communication media contributes to formation of the teenager's "worldview", his preferences in life style, behavioral strategies, intergroup norms. The effect of influence on the audience is successful in that case, if, being based on the whole social-psychological range of norms, values, habits, moods and motivations of this society, the text creators appeal to thinking patterns, dominant in the audience. Thus, the analysis of text content allows revealing the mechanisms of influence on stereotypes of mass consciousness, preferable behavioral models, information awareness.

At present, this problem is one of the most serious ones. The freedom of word, understood too widely, destroys ethic and moral bans. Many modern journalists perceived the freedom of word as a synonym to permissiveness in their speech behavior. The language of press has, apart from slang and colloquialisms, the elements of sublanguages, limited by extralinguistic features. Essentially, all, what was acquired in free everyday speech (and much extra), is now admitted in written texts, in any case, in the sphere of mass media. The literary use includes the whole groups of images, previously typical only of the vernacular. A typical example - the notions to take a swipe at, beefed out, to get goat, to get somebody involved into something, in the meaning "to make an object of any criminal actions".

The expansion of slang expressions, especially connected with the criminal sphere, reduces not only the moral level of discussion of socially important topics with the mass media. The dominance of criminal slang, which describes not only the criminal environment in mass communication, but also the official politics and economy, signalizes about one more urgent problem, emerging in the years of post-Soviet political and economic reforms - this time, the problem of not moral-ethic, but cognitive plan (cognitive, and being reflected in practical activity). It is connected with the fact, that comparison of political-economic realias and leaders to the criminal world and its "crime bosses" results in creation of specific criminal worldview, described by means of wide combination of metaphoric expressions ("protection", "showdown", "put-down" and others), and presenting an important fragment of the integral view of the world. Argotisms bear the corporative-reserved character in all normative-oriented texts, irrespectively of their definite functional-stylistic peculiarities. Previously, argotisms were used in thematically oriented publications, aimed to depict the specificity of existence of social declass layer, however, at present, the slang words of criminals, gamblers, drug addicts are used in texts of any topic. Many people even do not know, that such widely used words and expressions, as "clubbing circuit", "keif", "to swerve on", "a boy Friday", "blow top", "for real", "set a time", "droid" have exactly such origin. The use of such vocabulary in the mass media provides the naming of realias, typical of this speech community, not having neutral, in stylistic relation, generally accepted notions, and characterizes the presented social environment from the viewpoint of specificity of its existence. It is necessary to note, that the definite aspect of transmission of such expressions can also have a negative impact on social development in the sphere of social collisions and conflicts (Dmitriev, 2011).

As per Sapir-Whorf hypothesis, the language has a strongest impact on consciousness, determining its specificity. "The mass media and advertisement are the most powerful conducting filters, using the language as its instrument. At present, it is this language, the language of modern mass media that "organizes" the readers' consciousness". Easiness and frequency, with which journalists use such expressions, legalizes them, assures the reader (especially, the young one), that he should speak in this way. In this relation, the authority of the mass media is based not on the correctness, normalization of the used devices, but on the increased efficiency, decisiveness and continuity of influence. The vernacular is frequently the exponent of special vulgar and even criminal ideology. A notion, unworthy to gain the right for existence, enters into our life together with the slangy word. Not only language, but also the speaker's worldview becomes primitive and callous. The mass media, one way or another, transforms the system of concepts of the society as a whole. Interpreting current reality, or precedent-setting phenomena, or cultural topos, the journalism, wishing or not, increases the value of these interpretations and forms their evaluative characteristics in the addressee's consciousness. The degree and the extent of responsibility of the mass media for this activity are predetermined by the choice itself, requiring from the journalist's linguistic personality the increased speech and cultural competence.

\subsection{Structure-forming parameters of Russian PR-discourse}

The social institute of public relations appeared in Russia in 1980 of the XX century, while in the USA it appeared in the 1910-1920 of the XX century, and in the Western European Countries it appeared after the Second World War. At the first development stages, the native PR had neither theoretical, nor methodological, nor educational bases. However, native PR was rapidly changing, characterized by, as mentioned by D.P. Shishkin, "forcedly intense", to some degree, artificial features" (Shishkin 2004, p. 145). The subjective system of the PR-discourse is gradually developing: on the one 
hand, there appear the subjects, who are aware of the need in public relations and acting as clients, on the other hand there are the contractors, and the audience, for which the results of the PR-activity are meant, is being formed. The clients are the political, state, social, the first and official bodies, communities, united in accordance with socialdemographic, confessional, ethnic etc. features, social organizations, social institutes etc. The client is the subject, possessing PR technologies, a professional PR-man or agency, of the technological subject of the PR (Krivonosov and others, 2012). In the beginning of the 1990 of the XX century, PR agencies started to appear in Russia, PR-departments were organized in the mass media and the first department of such type was organized in the newspaper "The Komsomolskaia Pravda" in 1993.

The professional PR culture is formed on the basis of the approved documents: "The Declaration of Professional and Ethic Principles in the Sphere of Public Relations" (1994), "The Charter of Principles of Cooperation and Competition at the Russian Service Market of Public Relations" (1997), the Charter "The Political Consultants for the Fair Choice" (1999). The committee consists of the representatives of both RASO, and AKOS, VOST, PAPA, IAA. Finally, during RASO general meetings, there was approved the document "The Main Principles of Professional Certification in the Sphere of Public Relations", where the highest governing body appealed to all concerned organizations and all community to express their suggestions about the certification criteria and methods. Then, the Social Committee developed "A Code of Professional Certification in the Sphere of Public Relations", and also the system of professional criteria, which determines the level of education, experience and professional qualities of claimants upon the certificate. It shall be noted, that the certification is free-will and is carried on the basis of declarative-registration, but not the permissible scheme. It is curious, that the certification is oriented at both legal bodies and individuals.

On September 26 in 2001, the Russian Association on Public Relations (RASO) approved a Russian Code of Professional and Ethic Principles in the Sphere of Public Relations. It included general professional principles, principles of communication with the client, with the colleagues in the sphere of public relations, with the mass media and the representatives of other professions. The creation of PR Code became the significant moment in institutionalization of PR-sphere in Russia.

Besides, the first Memorandum of Russian Academy on Public Relations "About the Status of Public Relations in the Russian Federation in 2010-2011" was passed based on public discussions on the portal www.raso.ru. This document determined social and professional priorities of activity of the Russian Association of Public Relations in 2011. The public priorities involved such activity areas, as the interaction of state, business and public, social tolerance, childhood, healthy lifestyle, communications in scientific and innovative spheres, regional development and advancement of territories.

Subject belonging and thematic repertoire of the PR-discourse is determined by the client's sphere and demonstrates poly-objectivity. We bear in mind, that the phenomena of reality from different social spheres and different in volume can act as the objects of PR-discourse. To evaluate subject belonging of the PR-discourse, it is possible to use the formula of Wayy-Mazur, who consider PR as an umbrella, under which are such spheres, as corporative communications, problem management, publicity of product, relations with investors, financial communications, lobbying, social relations, relations with the mass-media, communal problems, crisis management, event management, sponsorship, set of services, included here (Selezneva, 2014).

Such wide thematic repertoire of the PR-discourse results in genre variety, where it is possible to distinguish primary basic genres (as per the terminology of A.D. Krivonosov): press release, backgrounder, fact-list, a list of questions/answers, by-liner, invitation, remarks to reporters, congratulation, biography, trendy article, trendy interview, case-story (Krivonosov, 2001). The texts of these genres come from the basic PR subject, contain information, contributing to the increase of publicity capital of the PR subject, function in the sphere of public communication.

\subsection{Genre variety of modern business discourse}

Nowadays, business communication, as a type of social communication, got the scaling value. Purposeful speech activity, subject to strict rules, exist, firstly, in such forms, as speech-presentation, public address, business conversation, the basic forms of which are the interview, business negotiations and telephone conversation. Frequently, business communication is provided when appealing to question-answer form, that is why, in modern business communication, it is in high demand to know different type of questions (informative, alternative, suggestive, knots of the matter etc.) on the professional level (Makarov, 2003).

The most important component of the modern business discourse is the business press, which, on the one hand, shall "provide the informative demands of the business activity, publishing the material (including the statistical, promotional, legislative etc.), in order to create the information field, promoting the development of business (Sergachev, 
2000), and on the other hand, can involve "any newspaper with free-standing insert, as this section of publication stimulates and even creates the demand" (Sidorin, 2007). In the first half of the XIX century, the printed press finally formed the features of business press, characterized by efficiency and information authenticity, presented in the form of articles, reports, opinions, forecasts, economic thematic, pragmatic aspect angle of data presentation and its strict selection.

Written forms of business communication in Russia are rooted in high antiquity; they are connected with the formation of one of the most important pedantic style of Russian language, presented in the system of functional styles official. The first charters - loan, mortgage, testamentary - reflected legal relations of the Kievan Rus. Linguistic features of Russian document texts (composition, address, date and signature in the end of the document, the use of administrative, juridical, economic etc. vocabulary) were formed in Russian language of the business communication by the XVII century.

Modern business communication is connected, first of all, with such written varieties of business communication, as documentation, business, official correspondence. The experience, accumulated for centuries, was expressed in the appearance of stable speech formulas, which are still used in modern official correspondence, firstly, in etiquette letters, presenting separate kind of business letter, for instance, "Ladies and Gentlemen", "have the honor to suggest you", "we are assure you in advance, that" and others.

The etiquette formulas, used by the business letter compiler, correspond to speech situation of greeting, farewell, excuse, request, congratulation, invitation. Not being strictly regulated and subject to GOST, as distinct from internal documents, etiquette letters provide the possibility for speech creativity, determined by S.G. Ter-Minasova as "free creativity of the speaker" (Ter-Minasova, 2004).

Wide thematic repertoire of modern business discourse was reflected in genre variety of documents, among which it is possible to distinguish basic genres, presented in different sub-styles of official-business style: diplomatic, administrative-management, legislative. Thus, for instance, with different norms of compositional and juridical execution of ultimatum, note, notification or order, their content can be quite identical, the same, as the information content of obsolete form of "formal reply", which was popular in Don during Aleksey Mikhailovich governance, with modern lettersreplies.

Due to the study of business discourse, the problem of genre forms remains relevant and open. Each genre of the document has its own history, formed within centuries, distinctive linguistic features. The use and selection of definite patterns and cliche, used in the text, conveys in documents the motivation of speech action ("As per the minutes of meeting", "in view of the above", "you have my apologies for"). The cards - the combination of document requisites, located in fixed sequence, which, in their turn, are understood as the document text fragments. The requisites present the obligatory information fragment of the document; they constitute the basis of document texts (as per definition of S.P. Kushneruk). Each genre of the document has its stable set of requisites, which determines the linguistic character of business paper.

\section{Results and Discussion}

Message is an important linguistic function of the texts, created in official style. Voluntary character of presentation in documents is connected with their main task - to inform of the happening events, to record the facts (Kushneruk, 2012). That is why the success of business-communication depends on precision, high frequency of use, awareness of the commercial paper name. The document title, which is the "peculiar interstition between the system of conditions of document communication, formation rules and document linguistic execution, between text functioning and its structure" (Kachalkin, 2002), reflects the informative constituent of the business paper.

Existing in different forms, types and genres, the modern business discourse takes up firm leading positions among the technologies of business-communications and provides the process of two-way communication; its participants are, first of all, the organizations of any type of property. The study of different linguistic parameters of the modern business discourse presents a doubtless discourse for modern science.

It is also necessary to note, that the study of structure-forming parameters of the PR-discourse showed the following: firstly, public relations play an important and noticeable role in modern information-communicative space; secondly, at present, it is possible to speak about the formation of native PR-discourse, which can become the study object of the communicative linguistics. 


\section{Conclusion}

The information-communicative space is built and developed thanks to implementation of information technologies, and thanks to the changes, taking place in social sphere. Modern social sphere is presented by different social institutes (education, culture, health services, jurisdiction, politics etc), and, from the viewpoint of sociolinguistics, it can be considered as a combination of institutional or professional discourses: publicistic, business, military, pedagogical, scientific, religious, politics, sport, theatrical, medicine and others. We evaluate the social sphere as the conditions, required to produce the professional discourse; they present a net of constraints, which serve to select the phenomena of reality, aimed at production of texts of different genres.

\section{References}

Bhatia, V.K. (2010). Interdiscursivity in professional communication. Discourse \& Communication, 4 (1), 32 - 50

Deik, T.A. (1989). Language. Cognition. Communication (pp: 312). Moscow: Progress.

Krivonosov, A.D. (2001). The genres of PR-text (pp: 135). St. Petersburg: The Laboratory of the Instant Print of the Journalism Department of the St. Petersburg State University.

Krivonosov, A.D., Filatova, O.G. \& Shishkina, M.A. (2012). Theoretical frameworks of public relations (pp: 384). St. Petersburg: Piter.

Selezneva, L.V. (2014). Public relations in information-communicative space. Scientific Relations and Developments, Modern Communication Science, 3 (2), 24-29.

Schiffrin, D. (1990). The language of discourse: connections inside and out. Text, 10, 97 - 100.

Shishkin, D.P. (2004). The history of PR in Russia: periodization problems. Petersburg PR school: from theory to practice (pp: 143-150). St. Petersburg: The World Rose.

Federal Law of RF "About Participation in International Data Exchange" \#85-FL retrieved July, 04, 1996, from http://www.base. consultant.ru/cons/cgi/online.cgi?req=doc;base=LAW; $n=48401$.

Fuko, M. (1996). The order of discourse. The will to the truth: beyond the knowledge, power and sexuality. Works of different years (pp: 49-96). Moscow: Kastal.

Sergachev, V.Ya. (2000). Business press of the region: the state and development perspectives (pp: 198). St. Petersburg.

Sidorin, A. (2007). Business press: what is it? Business press of Russia: the present and the past, retrieved from http://www.dzyalosh. ru/01-comm/books/delov-pressa/1-sidorin.html.

Ter-Minasova, S.G. (2004). Word combination in scientific-linguistic and didactic aspects (pp: 67-89).

Kushneruk, S.P. (2012). Document linguistics (pp: 253). Moscow: Flinta; Science.

Kachalkin, A.N. (2002). The name of Russian document. Russia Speech: Scientific-Popular Magazine, 1, 71-76.

Kazaryan, I.R. (2011). Communications as a basis of efficient staff management. Chita: ChitSU.

Dmitriev, A.V. \& Latynov, V.V. (1999). Mass communication: the limits of political influence. Moscow: MSEC.

Dmitriev, A.V. (2011). Social conflict (pp: 60). St. Petersburg: St. Petersburg State University.

Dmitriev, A.V. \& Makarova, I.V. (2003). Non-formal communication: essays of theory and practice. Moscow: Modern Humanitarian University.

Morozova, L.A. (2004). Term-knowledge: the bases and methods. Moscow: Prometheus.

Makarov, M.L. (2003). The bases of discourse theory. Moscow: Gnosis. 